\title{
Development and Piloting of National Injury Surveillance System of Sri Lanka
}

\author{
Achala U. Jayatilleke ${ }^{\star 1}$, Diana Samarakkody ${ }^{2}$, Achini Jayatilleke ${ }^{3}$ and Samantha \\ Wimalaratne ${ }^{2}$
}

${ }^{1}$ Postgraduate Institute of Medicine, University of Colombo, Colombo, Sri Lanka; ${ }^{2}$ Ministry of Health, Colombo, Sri Lanka; ${ }^{3}$ University of Tokyo, Tokyo, Japan

\section{Objective}

Designing, developing and piloting a web-based Injury Surveillance System for Sri Lanka.

\section{Introduction}

In Sri Lanka, a major drawback in injury prevention is the lack of complete, accurate and timely data. To fulfill this data need, in 2006, Sri Lanka's Trauma Secretariat piloted an Injury Surveillance System (ISS) in four hospitals. This comprised of two parts: a paper-based data collection tool (Trauma Surveillance Record or TSR) and its corresponding software application. TSR recorded ICD-10 Chapter XIX codes related to the diagnoses of injuries, but did not record the Chapter $\mathrm{XX}$ codes pertaining to external causes of morbidity which provide essential knowledge for injury prevention. The software application was built using proprietary technologies that could lead to increased costs and associated dependencies with vendors. The system was unable to comply with the changing data needs of the Ministry of Health $(\mathrm{MoH})$ without a major retooling. Consequently, in 2011, the $\mathrm{MoH}$ made changes in the TSR, but the software application was unable to handle those changes. The ISS was evaluated by three independent teams which recommended discontinuing its use and suggested the development of a new system.

\section{Methods}

First, the authors, with a group of public health and informatics experts identified both functional and non-functional system requirements of the new ISS by visiting hospitals and meeting primary stakeholders. Then, the financial, technical, operational and ethical requirements were documented. In addition, the existing paper based data collection tool (TSR) was revised and a new tool (ISR) was created by removing redundant data elements and adding new ones. In the new ISS, the paper based data collection process begins at the time of admission and continues until the patient is discharged or dies. Subsequently, the patient's ICD-10 diagnosis codes and final disposition data become available. These data are then entered into the electronic application. The new application was developed using a distributed system architecture. A central server was located in the $\mathrm{MoH}$ and local servers were located in each hospital. Captured injury data were initially saved in the local server which synchronizes with the central server when internet connectivity becomes available.

\section{Results}

Piloting of the new ISS took place in March and April of 2013, at the Base Hospital, in Horana with data from 654 patients admitted with traumatic injuries. The new system addressed several deficiencies of the previous system (Table 1). Its distributed nature allowed restoring local databases from its mirror in the central server or vice versa; this is especially important to prevent losing data. Backing up data is paramount given the prevalence of power failures. In addition, the paper based tool enables continuous data collection during electricity or computer failures. We used open source software to decrease the initial costs and reduce dependency on proprietary technologies.
Additionally, the new ISS was made flexible enough to incorporate or modify data elements as needed. Finally, the new application includes ICD-10 codes from chapters XIX and XX; this new information will enable improving injury prevention policy decisions.

\section{Conclusions}

Our testing showed that the new ISS provides a feasible and sustainable mean of injury surveillance in Sri Lanka. Settings with limited informatics resources can learn from our approach to overcome the deficiencies of a faulty ISS; A better ISS, might use available resources, open source software and accommodate changing data needs without incurring in major modifications.

Evolution of Injury Surveillance System (ISS) in Sri Lanka

\begin{tabular}{|c|c|c|c|}
\hline Components of ISS & Characteristics & $\begin{array}{l}\text { Previous ISS(2006) } \\
\end{array}$ & New ISS(2013) \\
\hline \multirow{2}{*}{$\begin{array}{l}\text { Paper based data } \\
\text { collection tool }\end{array}$} & Name & $\begin{array}{l}\text { Trauma Surveillance } \\
\text { Record (TSR) }\end{array}$ & $\begin{array}{l}\text { Injury Surveillance } \\
\text { Record (ISR) }\end{array}$ \\
\hline & Codes included & ICD 10 chapter XIX & $\begin{array}{c}\text { ICD } 10 \text { chapter XIX \& } \\
\text { XX }\end{array}$ \\
\hline \multirow{8}{*}{ Software Application } & Version & 1.0 & 2.0 \\
\hline & Technologies used & $\begin{array}{c}\text { Proprietary } \\
\text { (MS SQL Server, VB) }\end{array}$ & $\begin{array}{l}\text { Open source } \\
\text { (MySQL, PhP) }\end{array}$ \\
\hline & Database & Standalone & Distributed \\
\hline & $\begin{array}{l}\text { Incorporate changing } \\
\text { data needs }\end{array}$ & No & Yes \\
\hline & Data back-up & No & Yes \\
\hline & Validate data & No & Yes \\
\hline & $\begin{array}{l}\text { Handle missing } \\
\text { information }\end{array}$ & No & Yes \\
\hline & Generate flexible reports & No & Yes \\
\hline
\end{tabular}

\section{Keywords}

Injury Surveillance; Sri Lanka; Public Health

\section{Acknowledgments}

This project was supported by a grant from the US' CDC through TEPHINET, a program of the Task Force for Global Health, Inc. Contents of this report are solely the responsibility of the authors and do not necessarily represent the views of The Task Force for Global Health, Inc., TEPHINET, or the CDC.

\section{*Achala U. Jayatilleke}

E-mail: achala@sItnet.lk 